\title{
The Trade and Welfare Effects of State Trading in China
}

\author{
Steve McCorriston \\ School of Business and Economics \\ University of Exeter \\ United Kingdom \\ (S.McCorriston@exeter.ac.uk) \\ Donald MacLaren \\ Department of Economics \\ The University of Melbourne \\ Australia \\ (D.MacLaren@unimelb.edu.au)
}

Contributed Paper prepared for presentation at the International Association of
Agricultural Economists Conference, Beijing, China, August 16-22, 2009

Copyright 2009 by Steve McCorriston and Donald MacLaren. All rights reserved. Readers may make verbatim copies of this document for non-commercial purposes by any means, provided that this copyright notice appears on all such copies. 


\title{
The Trade and Welfare Effects of State Trading in China
}

\section{Steve McCorriston and Donald MacLaren}

\begin{abstract}
:
State trading is a common feature in the management of imports and exports of agricultural products and it has been a long-standing feature of China’s agricultural trade regime. While the use of state trading was modified by China's accession to the WTO, it remains a dominant feature for some commodities, even although there have been recent attempts to diminish its importance. In this paper, we review the role that the state trading enterprise (STE), COFCO, continues to play in the importing and exporting of some agricultural commodities. We then review the economic theory that has been developed to measure the tariff equivalent of importing state trading enterprises. Finally, we apply that theory through a calibration exercise to measure the tariff equivalent of COFCO in China's import market for wheat. We find that the trade distortions created by COFCO remain important as do the associated welfare effects.
\end{abstract}

Keywords: Trade Policy; State Trading Enterprises; China 


\title{
The Trade and Welfare Effects of State Trading in China
}

\author{
Steve McCorriston and Donald MacLaren
}

\section{Introduction}

State trading is a common feature in the management of imports and exports of agricultural products in a number of countries. China is no exception. While the use by the Chinese government of state trading was curtailed by the country's accession to the World Trade Organization (WTO) in 2001, it remains a dominant feature for some commodities. State trading arises where a government alters market structure in order to achieve specific domestic objectives for either producers or consumers of a commodity. This change in structure is achieved through the granting of exclusive rights to the state trading enterprise (STE) to buy and to sell in either the domestic market or in the international market or in both. An STE is, therefore, a marketing firm and not a production firm. ${ }^{1}$ This distinction is important in the economic modelling of STEs. It has been shown in recent research by McCorriston and MacLaren (2005, 2007) that, in general, the granting of exclusive rights to an STE causes trade to be distorted when compared with an industry composed only of profitmaximising firms. In particular, it has been shown that an importing STE acts as equivalent to an import tariff and an exporting STE acts as equivalent to an export subsidy. ${ }^{2}$

However, these general conclusions about the trade effects of STEs are dependent on three characteristics of the market in which the STE operates. The first characteristic is the objective given to the STE by government. This objective may be biased either towards producers or towards consumers. The second characteristic is the market structure that would exist in the absence of the STE. For example, there may or may not be a small number of firms, the good may be homogeneous or differentiated and there is the decision that the firms are assumed to make about the choice of strategic variable. The third characteristic is the

\footnotetext{
${ }^{1}$ In the Understanding on the Interpretation of Article XVII [of GATT 1994] a state trading enterprise is defined as:

'Governmental and non-governmental enterprises, including marketing boards, which have been granted exclusive or special rights or privileges, including statutory or constitutional powers, in the exercise of which they influence through their purchases or sales the level or direction of imports or exports.' (WTO, 1995:25)

${ }^{2}$ Despite their legality, there remains disquiet amongst some Members of the WTO that STEs engage in 'unfair' practices in international trade. It is for these reasons, amongst others, that STEs, and especially exporting STEs, have been the subject of negotiation in the Doha Round in the WTO. For a recent statement about exporting STEs in this context, see WTO (2008).
} 
extent of the exclusive rights enjoyed by the STE. At one extreme, the exclusivity may be complete in the sense that the STE has sole rights to trade in the domestic and international markets; at the other, the STE may have to compete with private firms in both of these markets. In between, there may exist exclusivity for the STE in either the domestic or the international market and competition with private firms in the other. Taken together, these three characteristics make the analysis of the economic effects of STEs less than straightforward because each combination of characteristics causes a discrete change in the equilibrium market structure and, hence, in the nature and the extent of the trade distorting effects of the STE.

The objective in this paper is to illustrate certain aspects of this assertion using the example of the China National Cereals, Oils and Foodstuffs Import and Export Company (COFCO). This important STE has been the mechanism through which the National Development and Reform Commission (formerly, the State Development and Planning Commission) has sought to balance supply and demand in the internal market for several agricultural commodities. This central planning activity has had the objectives of achieving self-sufficiency, food security and price stabilisation. Although membership of the WTO has forced some changes on the operations of COFCO, nevertheless, it remains important for the importation of several commodities, for example, wheat, maize, rice and vegetable oils; and for the exportation of others, for example, maize, rice and soya beans.

One of the important changes that has flowed from the membership of the WTO is that COFCO no longer has exclusive rights to the entire import quota for those commodities for which there exist tariff quotas. Some part of the quota has been reserved for private firms. It is the interaction of these firms with COFCO that is analysed below in sections 3 and 4.

As well as intervening at the border, governments in China at both the central and provincial levels intervene in domestic markets for agricultural products. Over time, the objectives being pursued and the policy instruments being used have altered. In particular, instead of taxing the agricultural sector, with the important exception of wheat, the sector is increasingly being subsidised (OECD, 2005). At the same time, private firms are playing a greater role domestically in the marketing and distribution of agricultural commodities. Therefore, although there remains state intervention in both the domestic and import markets, that intervention no longer reflects the exclusive rights of STEs.

The plan of the paper is as follows. In section 2 a simplified model of the import case is described through which the effect of the firm's objective function on trade is illustrated, as 
well as the trade effect of varying the structure of the industry that would exist in the absence of the STE. ${ }^{3}$ This model then provides intuition for the more detailed modelling of COFCO that is undertaken in section 3. In section 4 the trade and welfare effects of COFCO are calculated using a calibration exercise with specific functional forms. In section 5 , the conclusions obtained about the trade and welfare effects of COFCO are summarised.

\section{A Simplified Model of an Importing STE}

In order to abstract initially from the interaction on the supply side between the domestic and import markets, assume that the market for a single good is an open one, that the country is large and that there is no domestic production. Furthermore, assume initially that there is only one firm. This simplification clarifies the role of the firm's objective function and the number of firms in determining the equilibria.

Let the inverse domestic demand function be:

$$
p=p(q) \text { where } p^{\prime}(q)<0, p^{\prime \prime}(q) \geq 0
$$

where: $p$ is the consumer price and $q$ is the quantity imported. The inverse import supply function is:

$$
p_{m}=p_{m}(q) \text { where } p_{m}^{\prime}(q)>0, p_{m}^{\prime \prime} \geq 0
$$

where: $p_{m}$ is the border price of imports and $p(0)>p_{m}(0)>0$. The weighted objective function is:

$$
\begin{aligned}
W & =\alpha_{1} C S+\alpha_{2} \pi \\
& =\alpha_{c} C S+\pi
\end{aligned}
$$

where $\alpha_{c} \equiv \alpha_{1} / \alpha_{2}$ is the weight that the firm places on consumer surplus relative to the weight on profit, the latter being normalised to unity. Consumer surplus is given by:

$$
C S=\int_{0}^{q} p(z) \mathrm{d} z-p q
$$

and profit ${ }^{4}$ by:

$$
\pi=\left(p-p_{m}\right) q
$$

The first-order condition from maximising equation (3) with respect to imports is:

$$
p+q p^{\prime}\left(1-\alpha_{c}\right)=p_{m}+q p_{m}^{\prime}
$$

A private firm is assumed to maximise only profit because it places no weight on consumer surplus, i.e., such a firm will set $\alpha_{c}=0$. An STE is required by government to place some

\footnotetext{
${ }^{3}$ The analysis in this paper is restricted to the import case because the model required for the export case is quite different.

${ }^{4}$ It is assumed that the only cost incurred by the firms is the cost of procuring imports.
} 
positive weight on consumer surplus, i.e., it sets $\alpha_{c}=1 .^{5}$ Thus, for the private firm, which will be referred to as the benchmark, the first-order condition is:

$$
p+q p^{\prime}=p_{m}+q p_{m}^{\prime}
$$

and for the STE it is:

$$
p=p_{m}+q p_{m}^{\prime}
$$

The profit-maximising firm equates marginal revenue with marginal expenditure while the STE equates consumer price and marginal expenditure. Therefore, while both the private firm and the STE exploit their buying power with respect to exporters, they differ on the selling side. The private firm exploits its selling power but the STE does not because it is pursuing an objective which takes into account the level of consumer surplus.

From equations (7) and (8) it is intuitive that the STE will import more than the benchmark firm and in so doing will increase consumers' welfare by lowering the consumer price. In order to prove the first part of this proposition it sufficient to note: first, that for any positive level of imports, the demand function lies strictly above the marginal revenue function (i.e., $\left.p(q)>p(q)+q p^{\prime}(q)\right)$; and second, that the marginal expenditure function has a positive but not infinite slope. It follows that the marginal expenditure by the STE exceeds that by the benchmark and, therefore, that the quantity imported by the STE exceeds that by the benchmark. Thus, the consumer price is lower and consumers' welfare is higher than in the benchmark. The other component of social welfare is profit. Profit in the benchmark will exceed that for the STE. Hence, there is some ambiguity about which of these two equilibria generates the greater social welfare ( $W$ in equation (3)).

With the STE importing more than the profit-maximising firm, it acts equivalent to an import subsidy. The size of this subsidy equivalent could be calculated if specific functional forms were chosen for equations (1) and (2) and specific parameter values used. This is the approach used below in section 4. In other words, in a quantitative model, it is possible to answer the question: what is the value of the import subsidy that would induce the private firm to import as much as does the STE?

Now assume that there are $n$ identical firms which compete on quantity imported. Then the equilibrium in the benchmark is found from the intersection of the perceived marginal

\footnotetext{
${ }^{5}$ In general, the STE could choose a weight smaller than unity but that choice does not affect in a qualitative sense the conclusion to be drawn here about the trade distorting effect of the STE.
} 
revenue function and the perceived marginal expenditure function. ${ }^{6}$ When $n=1$, the equilibrium is that defined in equation (7) and it has been concluded already that the STE acts like an import subsidy. When $n$ increases from unity, the $M E^{*}$ and $M R^{*}$ functions rotate to the right and the equilibrium quantity imported will also move rightwards towards the perfectly competitive outcome, the equilibrium towards which the Cournot equilibrium tends as $n$ tends to infinity. Now, because the quantity imported by the STE and by a perfectly competitive industry are each fixed, there must be some value of $n$ for which the quantity imported by the oligopsony/oligopoly exceeds that of the STE. Therefore, the STE will switch from being equivalent to an import subsidy to being equivalent to an import tax, i.e., a tariff. As $n$ increases, so too does the size of the tariff equivalent because the quantity imported in the benchmark continues to increase relative to the fixed quantity imported by the STE. Therefore, there is some $n$ beyond which overall social welfare in the benchmark may exceed that with the STE.

The third characteristic of the market is the extent of the exclusive rights given to the STE by government. Assume that the STE is partially de-regulated and it has to compete for import procurement with a single, profit-maximising firm. In order to neutralise the effect of the number of firms on the equilibrium, let the relevant benchmark be a Cournot duopoly/duopsony. When $n=2$, the first-order conditions in the benchmark are given by:

$$
\begin{aligned}
& p+q_{1} \partial p / \partial q_{1}=p_{m}+q_{1} \partial p_{m} / \partial q_{1} \\
& p+q_{2} \partial p / \partial q_{2}=p_{m}+q_{2} \partial p_{m} / \partial q_{2}
\end{aligned}
$$

where $q=\left(q_{1}+q_{2}\right), p=p\left(q_{1}+q_{2}\right)$ and $p_{m}=p_{m}\left(q_{1}+q_{2}\right)$. This resulting equilibrium will represent a greater level of imports than that in the solution to equation (7).

In the de-regulated environment, the STE no longer has exclusive rights and the conditions which defined its previous equilibrium (equation (8)) no longer pertain. The demand and supply functions are now defined as $p=p\left(q^{P}+q^{S T E}\right)$ and $p_{m}=p_{m}\left(q^{P}+q^{S T E}\right)$, respectively, where $q^{P}$ is the quantity imported by the private firm and $q^{\text {STE }}$ the quantity imported by the STE. The first-order conditions are:

$$
\begin{aligned}
& p+q^{P} \partial p / \partial q^{P}=p_{m}+q^{P} \partial p_{m} / \partial q^{P} \\
& p-q^{P} \partial p / \partial q^{S T E}=p_{m}+q^{S T E} \partial p_{m} / \partial q^{S T E}
\end{aligned}
$$

In order to determine the effect of the partial deregulation of the STE on trade and welfare, it is necessary to compare the equilibrium in equation (9) with that in equation (10). However,

\footnotetext{
${ }^{6}$ Perceived marginal revenue is defined as $M R^{*}=\frac{1}{n} M R+\left(1-\frac{1}{n}\right) p$ and perceived marginal expenditure as $M E^{*}=\frac{1}{n} M E+\left(1-\frac{1}{n}\right) p_{m}$
} 
instead of undertaking this task here, the implications of it are explored below in section 4 in a more realistic model with domestic procurement as well as imports. As will be shown in that section, the interaction between firms which are permitted to procure in both the domestic and the import markets has a fundamental bearing on the trade and welfare effects of an STE.

\section{A Stylised Model of COFCO}

In the simplified model in the previous section, it was assumed that there were no explicit trade policy instruments being used. However, in the case of wheat imports to China, this is not an appropriate assumption. Imports of wheat are subject to a tariff quota and, since 2001, COFCO has had exclusive rights to only 90 per cent of that quota. The remaining 10 per cent of the quota is available each year for the use of private firms which are successful in obtaining import licences. The in-quota tariff is 1 per cent and the out-of-quota tariff is 65 per cent (ABARE, 2006) and the annual quota is approximately 9 million tonnes. Since 2001, the quota has never been filled and, indeed, in 2003 the fill rate was only 5 per cent.

In principle, private firms which satisfy the criteria administered by the National Development and Reform Commission, may apply for a license to import. The amount that they import can exceed the quota but then they will face the out-of-quota ad valorem tariff of 65 per cent. All that is guaranteed to licensed firms is that they can gain access to 10 per cent of the import quota at the in-quota tariff rate. In practice, the quantities imported by these firms may be linked to decisions made by the National Development and Reform Commission about total imports and the imports required to be made by COFCO.

The modelling of the import regime for wheat needs to reflect the competition for imports between COFCO and these licensed firms. But it also needs to reflect the reality that some of these firms may also procure wheat in the domestic market in which they have to compete with state entities and other private firms which do not possess licenses to import. Therefore, in place of the single firm described in section 2, there are four distinct types of firms which operate in the China wheat market. On the import side, there is COFCO and a number of licensed firms. On the domestic side, some of these licensed firms compete for domestically procured wheat with two other players - with private firms, which do not import, and with state entities.

In outline, the structure of the model is as follows. Linear inverse domestic demand, inverse domestic supply and inverse import supply functions are assumed to enable the calibrated model to generate specific values for the variables of interest. It is also assumed that imported wheat and domestically produced wheat are differentiated. 
The inverse domestic and import demand functions are:

$$
\begin{aligned}
& p_{d}=a_{d}-b_{d}\left(n^{d} q^{d}+n^{L} q_{d}^{L}+Q_{d}^{S T E}\right)-\gamma\left(Q_{m}^{S T E}+n^{L} q_{m}^{L}\right) \\
& p_{m}=a_{m}-b_{m}\left(Q_{m}^{S T E}+n^{L} q_{m}^{L}\right)-\gamma\left(n^{d} q^{d}+n^{L} q_{d}^{L}+Q_{d}^{S T E}\right)
\end{aligned}
$$

where: $n^{d}$ is the number of firms procuring only from the domestic market and they each import the quantity $q_{d} ; n^{L}$ is the number of firms that are licensed to procure from both markets - they each procure $q_{d}^{L}$ from the domestic market and import $q_{m}^{L}$; total domestic quantity procured is $\left(n^{d} q^{d}+n^{L} q_{d}^{L}\right)=Q_{d}$ and total imports are $Q_{m}=Q_{m}^{S T E}+n^{L} q_{m}^{L}$. The last of these expressions is based on the assumption that the private firms are free to import and that their profit-maximising level of imports is less than 10 per cent of the import quota. If this assumption is not made, then the optimal quantity imported by the private firms (and COFCO) could exceed the quota and their first-order conditions would need to be modified to reflect the possibility that the import price could be $1.65 p_{w}$ instead of $p_{w}$ (ignoring the nuisance in-quota tariff rate of 1 per cent).

The domestic inverse supply function for wheat is given by:

$$
p_{A}=f+k\left(Q_{d}+Q_{d}^{S T E}\right)
$$

where $Q^{d}$ and $Q_{d}^{S T E}$ are the procurement levels of the private firms and the domestic state entities. The import inverse supply function is given by:

$$
p_{w}=F+K\left(Q_{m}+Q_{m}^{S T E}\right)
$$

where $Q_{m}=n^{L} q_{m}^{L}$ and $Q_{m}^{S T E}$ are imports by COFCO.

Let the objective function for the $j^{\text {th }}$ private, domestic firm be:

$$
\pi_{j}^{d}=\left(p_{d}-p_{A}\right) q_{j}^{d}, \quad j=1, \ldots, n^{d}
$$

The objective function of the $i^{\text {th }}$ licensed firm which operate in both markets is:

$$
\pi_{i}^{L}=\left(p_{d}-p_{A}\right) q_{d, i}^{L}+\left(p_{m}-p_{w}\right) q_{m, i}^{L}, \quad i=1, \ldots, n^{L}
$$

Profits from importing, $\pi_{m, i}^{L}=\left(p_{m}-p_{w}\right) q_{m, i}^{L}$, are more complex because of the tariff quota which has the potential to create a range of values for $p_{m}$. These range from the lower price of the world price plus the in-quota tariff to the higher price of the world price plus the out-ofquota tariff. The second complication is whether or not these firms are free to choose their level of imports or whether they are influenced by the National Development and Reform Commission. If they are free to choose, then this case is referred to below (Table 1) as the unrestricted case; when are not free to choose, this is referred as the restricted case. In the 
latter, it is assumed that there is a fixed coefficient, $v(0<v<1)$ linking imports by the private firms to the imports of COFCO, namely, $n^{L} q_{m}^{L}=v Q_{m}^{S T E}$ and $Q_{m}=(1+v) Q_{m}^{S T E}$.

COFCO's objective is given by:

$$
W=\alpha_{p} P S+\alpha_{c} C S+\pi_{d}+\pi_{m}
$$

where $\pi_{d}$ and $\pi_{m}$ are profits earned in the domestic and import markets, respectively. The state enterprise, when free to do so (the unrestricted case), chooses $Q_{d}^{S T E}$ and $Q_{m}^{S T E}$ to maximise the function $W$, given values for $\alpha_{p}$ and $\alpha_{c}$.

The first-order conditions are obtained from equations (11), (12) and (13). They are:

$$
\begin{aligned}
& {\left[\begin{array}{ccccc}
\left(n^{d}+1\right)\left(b_{d}+k\right) & n^{L}\left(b_{d}+k\right) & \left(b_{d}+k\right) & \gamma & n^{L} \gamma\left(1-\alpha_{c}\right) \\
n^{d}\left(b_{d}+k\right) & \left(n^{L}+\right)\left(b_{d}+k\right) & \left(b_{d}+k\right) & \gamma & n^{L}\left(b_{m}\left(1-\alpha_{c}\right)+k\right) \\
n^{d}\left[b_{d}\left(1-\alpha_{c}\right)+k\left(1-\alpha_{p}\right)\right] & n^{L}\left[b_{d}\left(1-\alpha_{c}\right)+k\left(1-\alpha_{p}\right)\right] & b_{d}\left(2-\alpha_{c}\right)+k\left(2-\alpha_{p}\right) & \gamma\left(2-\alpha_{c}\right) & n^{L} \gamma \\
n^{d} \gamma\left(1-\alpha_{c}\right) & n^{L} \gamma\left(1-\alpha_{c}\right) & \gamma\left(2-\alpha_{c}\right) & b_{m}\left(2-\alpha_{c}\right)+2 K & \gamma\left(n^{L}+1\right) \\
n^{d} & \gamma\left(n^{L}+1\right) & \gamma & \left(b_{m}+K\right) & \left(n^{L}+1\right)\left(b_{m}+K\right)
\end{array}\right]} \\
& {\left[\begin{array}{c}
q^{d} \\
q_{d}^{L} \\
Q_{d}^{S T E} \\
Q_{m}^{S T E} \\
q_{m}^{L}
\end{array}\right]=\left[\begin{array}{c}
a_{d}-f \\
a_{d}-f \\
a_{d}-f \\
a_{m}-F \\
a_{m}-F
\end{array}\right]} \\
&
\end{aligned}
$$

For known parameter values, these equations can be solved for the volume of imports and that volume would then be compared with the volume in the benchmark of $n$ Cournot firms and the import tax/subsidy equivalent of the STE computed. The first-order conditions for the $i^{\text {th }}$ firm from which the import volume in the benchmark, $Q_{m}=n q_{m, i}$, can be calculated are:

$$
\left(\begin{array}{cc}
\left(b_{d}+k\right)(n+1) & \gamma(n+1) \\
\gamma(n+1) & \left(b_{m}+K\right)(n+1)
\end{array}\right)\left(\begin{array}{c}
q_{d} \\
q_{m}
\end{array}\right)=\left(\begin{array}{c}
a_{d}-f \\
a_{m}-F-t^{e}
\end{array}\right)
$$

The solution of equation (17) provides the optimal volume of imports in the unrestricted case. Then setting the optimal volume of imports from equation (18), when aggregated over the $n$ firms, equal to the solution in equation (17) and solving for $t^{e}$, gives the import tax/subsidy equivalent of COFCO.

\section{The Trade and Welfare Effects of COFCO}

Data were obtained for the single year 2005/06 and the above equations (11-13) were calibrated using a method due to Dixit (1988). This calibration provides values for the 
intercept and slope parameters in these equations which, in turn, allow solutions from equations (17) and (18) to be calculated. Data for import quantities and unit value import prices were sourced from the FAO. Domestic production and sales data as well as prices at the downstream stage (in this case, wholesale prices) were sourced from USDA. To capture the bias in government policy that is reflected in equation (16), it was noted that the PSE (CSE) in the wheat sector in recent years has been negative (positive) reflecting a bias towards consumers. It was assumed that $\alpha_{c}=1.1$ and $\alpha_{p}=0.7$. Two sets of results were obtained. In the unrestricted case, they were obtained from equation (17) as set out above. In the restricted case, some modifications were required to reflect the linkage between imports by the private firms and by COFCO.

The results are given in Table 1 for particular values of the policy weights, for the number of private firms of both types and for the number of firms in the benchmark. The first result is that COFCO acts as an import subsidy in both of the cases shown. This result accords with the intuition developed in section 2 above and it reflects the government's objective of ensuring that consumers' welfare is taken into account by COFCO. ${ }^{7}$ The difference between the import subsidy equivalent in the two cases reflects the strategic interaction between COFCO and the licensed firms in the non-restricted case compared with the restricted case in which there is no such interaction.

Table 1: The Trade Distorting Effects of COFCO in the Chinese Wheat Market ${ }^{a}$

\begin{tabular}{|c|c|c|}
\hline \multirow[b]{2}{*}{ Variable } & \multicolumn{2}{|c|}{ Case } \\
\hline & Restricted & Non-restricted \\
\hline Tariff-equivalent of COFCO ${ }^{b}$ & -US\$28.9/tonne $(-14 \%)^{c}$ & -US\$17.9/tonne $(-8 \%)^{c}$ \\
\hline \multicolumn{3}{|l|}{ Net welfare effect (\%) ${ }^{b}$} \\
\hline \multicolumn{3}{|l|}{ China } \\
\hline Producer surplus & 39.1 & 40.2 \\
\hline Consumer surplus & 20.1 & 20.3 \\
\hline Profit & -99.4 & -99.2 \\
\hline Social welfare & 0.12 & 0.43 \\
\hline Exporters & 16.1 & 9.8 \\
\hline
\end{tabular}

Note: $\quad a$ Calculated using $v=0.5$ (in the restricted case), $\alpha_{c}=1.1, \alpha_{p}=0.7, n=10, n^{d}=7, n^{L}=2$

$b$ the percentage change measured from the benchmark

c ad valorem equivalent import subsidy

\footnotetext{
${ }^{7}$ If the policy weights are changed to reflect a bias towards wheat producers rather than consumers of wheat, the sign of the trade tax/subsidy equivalent switches from being a subsidy to being a tariff.
} 
Second, in both cases, the current market structure improves social welfare in China relative to that in the benchmark, albeit by only a very small percentage. The principal effect in China is through redistribution of welfare amongst the participants in the domestic market, namely, wheat producers, the profits of marketing firms and consumers. Relative to the benchmark of a 10-firm oligopsony/oligopoly, total profits are almost zero (the percentage change is -99), while producers gain by 40 per cent and consumers by 20 per cent. Third, the countries that export wheat to China benefit quite substantially from the current structure when compared with the benchmark. Taken together, these results would suggest that neither the government of China (given the apparent objectives/bias in government policy in China as currently reflected in the aggregate support data) nor the governments of the exporting countries would be willing to support trade negotiations in which this importing STE was to be banned. However, to the extent that the direction of agricultural policy applied in China will change to one with more support to producers, as noted above, this will result in a substantial tariff equivalent rather than an import subsidy equivalent. The existence of COFCO will then benefit producers, even more than under this set of policy weights, it will lower consumer welfare, resulting in lower national welfare and welfare losses for exporters. Under such circumstances, COFCO will become more of an issue for trading partners. The extent of this loss will also depend, as here, on the management of the quota licences for private firms.

\section{Conclusions}

State trading remains an important feature of China's international trade regime for agricultural products. It has been shown that the government's objective for the STE together with the extent of the exclusive rights enjoyed by it, as well as the market structure that would exist in the absence of the STE, are important in determining the trade and welfare effects of STEs. Through a calibration exercise applied to China's import regime for wheat, it was shown that the details of the interaction between COFCO and the private firms that have licenses to import do matter in drawing conclusions about the size of the trade distortion of COFCO. In particular it was shown that COFCO acts as an import subsidy, which benefits domestic consumers and producers, while reducing domestic profits, and which benefits the countries that are exporting wheat to China. 


\section{References}

ABARE (2006) Agriculture in China: developments and significance for Australia, Research Report 06.2, prepared for the Australian Government Department of Agriculture, Fisheries and Forestry, Canberra, March.

Dixit, A. D. (1988) 'Optimal Trade and Industrial Policies for the US Automobile Industry', in R. Feenstra (ed.) Empirical Methods for International Trade. Cambridge, MA: MIT Press.

McCorriston, Steve and Donald MacLaren (2005) 'The Trade Distorting Effect of State Trading Enterprises in Importing Countries', European Economic Review, 49: 16931715.

McCorriston, Steve and Donald MacLaren (2005) 'Do STEs Distort Trade?', European Economic Review 51(1): 225-246.

OECD (2005) 'Agricultural Policy Reform in China', OECD Observer Policy Brief, Paris, October.

WTO (2001). Accession of the People's Republic of China, Decision of 10 November 2001, WT/L/432, Geneva.

WTO (2008). Agriculture Negotiations: Revised Draft Modalities for Agriculture, TN/AG/W/4/Rev.3, Annex K, Geneva, http://www.wto.org/english/tratop_e/agric_e/agchairtxt_july08_e.htm. 